\title{
Stability Control of Deep Coal Roadway under the Pressure Relief Effect of Adjacent Roadway with Large Deformation: A Case Study
}

\author{
Houqiang Yang ${ }^{1}$, Nong Zhang ${ }^{1,2, * \mathbb{C}}$, Changliang Han ${ }^{1, *}$, Changlun Sun ${ }^{1} \mathbb{D}$, Guanghui Song ${ }^{1}$, Yuantian Sun ${ }^{1} \mathbb{D}$ \\ and Kai Sun ${ }^{3}$ \\ 1 Key Laboratory of Deep Coal Resource Mining, Ministry of Education of China, School of Mines, \\ University of Mining and Technology, Xuzhou 221116, China; yhq@cumt.edu.cn (H.Y.); \\ ts16020043a3@cumt.edu.cn (C.S.); ts19020040a31@cumt.edu.cn (G.S.); yuantiansun@cumt.edu.cn (Y.S.) \\ 2 Open Laboratory for Large-Scale Scientific Instruments, Jiangsu Normal University, Xuzhou 221116, China \\ 3 Zhongtian Hechuang Energy Co. Ltd., Ordos 017020, China; sunkai7225@163.com \\ * Correspondence: zhangnong@cumt.edu.cn (N.Z.); hanchangliang@cumt.edu.cn (C.H.)
}

check for

updates

Citation: Yang, H.; Zhang, N.; Han, C.; Sun, C.; Song, G.; Sun, Y.; Sun, K. Stability Control of Deep Coal Roadway under the Pressure Relief Effect of Adjacent Roadway with Large Deformation: A Case Study. Sustainability 2021, 13, 4412. https://doi.org/10.3390/su13084412

Academic Editor: Glen Corder

Received: 3 March 2021

Accepted: 14 April 2021

Published: 15 April 2021

Publisher's Note: MDPI stays neutral with regard to jurisdictional claims in published maps and institutional affiliations.

Copyright: (c) 2021 by the authors. Licensee MDPI, Basel, Switzerland. This article is an open access article distributed under the terms and conditions of the Creative Commons Attribution (CC BY) license (https:// creativecommons.org/licenses/by/ $4.0 /)$.

\begin{abstract}
High-efficiency maintenance and control of the deep coal roadway surrounding rock stability is a reliable guarantee for sustainable development of a coal mine. However, it is difficult to control the stability of a roadway that locates near a roadway with large deformation. With return air roadway 21201 (RAR 21201) in Hulusu coal mine as the research background, in situ investigation, theoretical analysis, numerical simulation, and engineering practice were carried out to study pressure relief effect on the surrounding rock after the severe deformation of the roadway. Besides, the feasibility of excavating a new roadway near this damaged one by means of pressure relief effect is also discussed. Results showed that after the strong mining roadway suffered huge loose deformation, the space inside shrank so violently that surrounding rock released high stress to a large extent, which formed certain pressure relief effect on the rock. Through excavating a new roadway near this deformed one, the new roadway could obtain a relative low stress environment with the help of the pressure relief effect, which is beneficial for maintenance and control of itself. Equal row spacing double-bearing ring support technology is proposed and carried out. Engineering practice indicates that the new excavated roadway escaped from possible separation fracture in the roof anchoring range, and the surrounding rock deformation of the new roadway is well controlled, which verifies the pressure relief effect mentioned. This paper provides a reference for scientific mining under the condition of deep buried and high stress mining in western China.
\end{abstract}

Keywords: stability control; deep coal roadway; deformation; pressure relief; coal pillar; surrounding rock control; bolt support

\section{Introduction}

With China's main coal mining center moving westward [1-3], the average mining depth of the western mining area continues to extend at the rate of 10-25 $\mathrm{m}$ per year $[4,5]$, which is about to reach the absolute deep coal mining of 700-1000 $\mathrm{m} \mathrm{[6].} \mathrm{Due} \mathrm{to} \mathrm{the}$ fact that the layout of double roadways can alleviate the imbalance of mining ratio and realize the rapid recovery of coal resources, some western mining areas still adopt double roadways after entering deep mining. They draw lessons from the layout of double roadway with large coal pillar used in shallow mining area, namely "one working face with three roadways" layout (the layout of double roadways) [7-9], in which the auxiliary transportation roadway is reserved as the return air roadway of the next working face with a 20-40 m coal pillar [10]. However, obvious defects are shown in the layout of double roadways. During the service period, the auxiliary roadways have experienced many times of mining disturbance, which is prone to severe contraction of roadway section, 
deformation, fracture, and instability, and even cannot continue to serve for the working face in the next section. At this time, it is the only choice to re-excavate the return air roadway of the next working face, and the selection of roadway excavation position becomes very important. As for the high gas mine that contains a connecting roadway, it is the only choice to look for the pressure relief area formed by roadway excavation and re-excavating the roadway along the residual roadway, in order to prevent the gas and other harmful gas from overflowing during driving.

For excavating roadway in pressure relief area, most of the existing researches focus on gob-side roadway excavating, using "voussoir beam theory" to analyze the pressure relief mechanism and the selection of reasonable position (coal pillar width). Zheng [11] developed a mechanical model of gob-side roadway overburdens to analyze the large deformation and stress field distribution. In order to mitigate the problem of the coal pillar extrusion and serious deformation that will occur in the gob-side roadway, Tai [12] developed the roof-cutting technology with a chainsaw arm and its equipment. Zhang [13] investigated the effects of dynamic loading to gob-side entries and optimized the support parameters; the field test results showed that the potential for loosening, deformation, and failure of the surrounding rock were effectively controlled. Wu [14] studied the initiation, propagation, and failure of cracks within this gob-side coal pillar during its formation by using the methods of field tests and numerical modeling. Zhang [15] had studied how to set narrow coal pillar along the edge of upper goaf in large coal pillar to excavate the roadway in this section. The stability and failure mechanism of coal pillar have also been widely studied $[16,17]$. The existing research results focus on the stability of narrow coal pillar and the reasonable width of section coal pillar. However, research on the problem of width choice in the coal pillar is not adequate. With the help of the pressure relief effect of the surrounding rock caused by the severe deformation of the residual auxiliary transportation roadway in the upper sectional working face, it is worth researching how to determine the width of the coal pillar in the return air roadway of the working face in this section by setting a narrow coal pillar along the broken roadway.

In view of the problems above, this paper takes the RAR 21201 of Hulusu coal mine as the engineering background, analyzes the pressure relief effect on the surrounding rock after the violent deformation of roadway, and probes into the feasibility of excavating new RAR 21201 near this deformed roadway 21102 (AHR 21102) after setting a narrow coal pillar. Equal row-spacing double-bearing ring support technology is proposed, and engineering practice has verified the pressure relief effect on the new roadway, which improves the controlling effect of surrounding rock.

\section{Project Overview}

\subsection{Roadway Location and Mining Relationship}

Hulusu coal mine is located in Ordos City, Inner Mongolia Province, China, with a depth of 650-900 m. It is a typical kind of Western deep buried mine. In the early stage of the mine, the "the layout of double roadways" method was adopted (Figure 1), in which the AHR 21102 served for the working face 21102. After the mining of the working face 21102, the AHR 21102 was reserved as the return air roadway of the working face 21201 in the second panel area, and a 30-m coal pillar was reserved between the working face 21102 and the working face 21102. As the result of severe deformation, most of the roadway sections have no value of roadway repairing, so it is considered to set up a new coal pillar along the west side of AHR 21102 and excavate RAR 21201 to serve working face 21201. According to the in-situ stress measurement data provided by the mine, the maximum horizontal stress is $24.74 \mathrm{MPa}$, the maximum vertical stress is $16.31 \mathrm{MPa}$, and the maximum minimum horizontal principal stress is $13.36 \mathrm{MPa}$. The angle of maximum horizontal principal stress is between $\mathrm{N} 20.4^{\circ}$ and $38.5^{\circ} \mathrm{W}$, and the direction of roadway axis is north-south direction, that is, the angle between maximum horizontal principal stress and roadway axis is between $\mathrm{N} 20.4^{\circ}$ and $38.5^{\circ} \mathrm{W}$. 


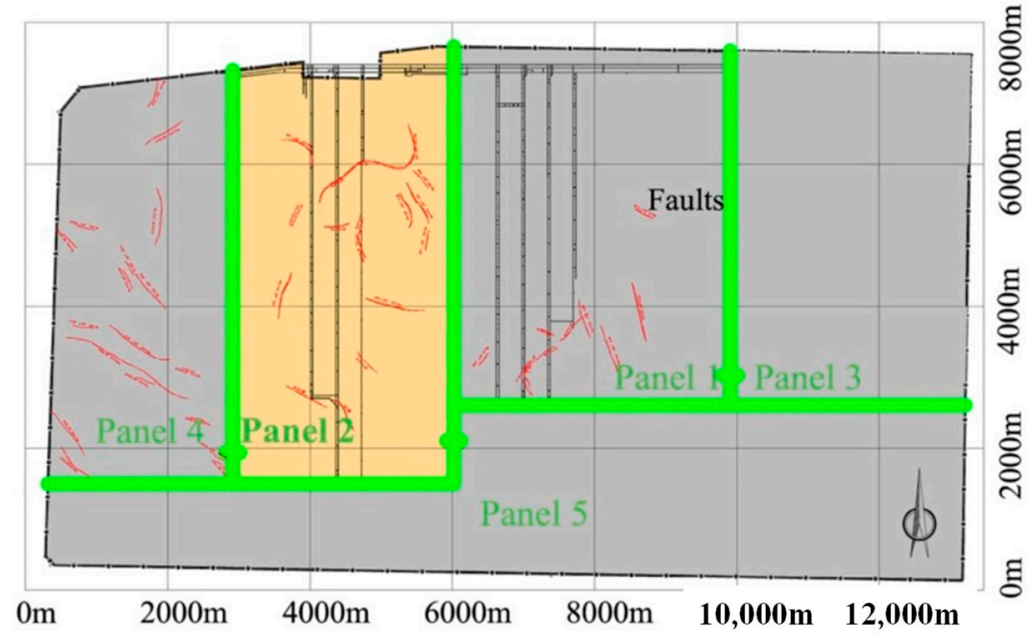

(a)

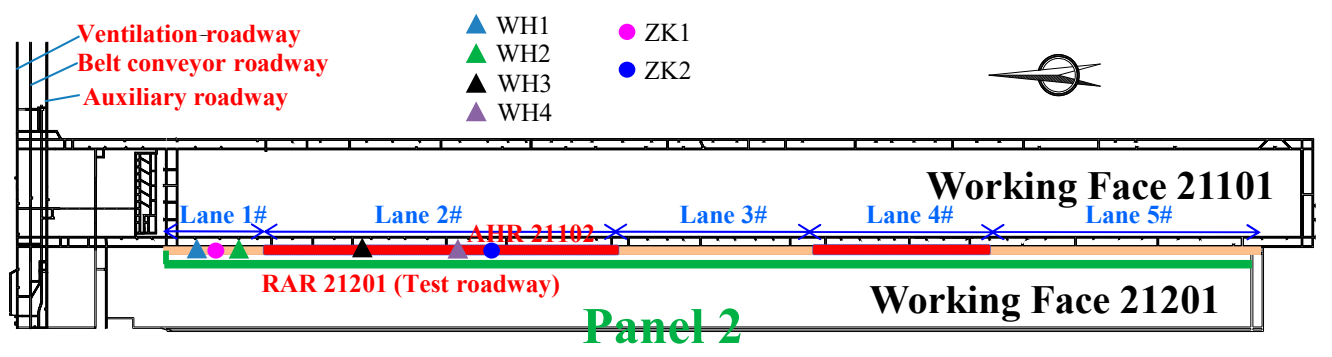

(b)

Figure 1. Roadway location and mining relationship. (a) General mining layout of Hulusu coal mine (reproduced from literature [18]); (b) geological conditions and layout of the test areas.

\subsection{Lithology of Coal Seam, Roof and Floor}

The average thickness of main mining $2-1$ coal seam is $2.79 \mathrm{~m}$, and the average buried depth is $626.65 \mathrm{~m}$. The immediate roof is sandy mudstone with an average thickness of $4 \mathrm{~m}$, and the floor is mainly sandy mudstone and fine-grained sandstone. The concrete occurrence and the mechanical parameters of the roof and floor strata are shown in Table 1.

Table 1. Distribution and mechanical parameters of strata.

\begin{tabular}{|c|c|c|c|c|c|c|c|}
\hline Number & Lithology & $\begin{array}{l}\text { Thickness } \\
\text { (m) }\end{array}$ & $\begin{array}{c}\text { Density } \\
\left(\mathrm{kg} \cdot \mathrm{m}^{-3}\right)\end{array}$ & $\begin{array}{l}\text { Bulk Modulus } \\
\text { (GPa) }\end{array}$ & $\begin{array}{c}\text { Shear Modulus/ } \\
\text { (GPa) }\end{array}$ & $\begin{array}{c}\text { Internal Friction } \\
\text { Angle }\left({ }^{\circ}\right)\end{array}$ & $\begin{array}{c}\text { Cohesion } \\
\text { (MPa) }\end{array}$ \\
\hline 3 & $\begin{array}{l}\text { Sandy } \\
\text { mudstone }\end{array}$ & 26 & 2530 & 2.56 & 2.36 & 36 & 2.16 \\
\hline 2 & $\begin{array}{l}\text { Fine grained } \\
\text { sandstone }\end{array}$ & 13 & 2873 & 21.01 & 13.52 & 42 & 3.2 \\
\hline 1 & $\begin{array}{l}\text { Sandy } \\
\text { mudstone }\end{array}$ & 4 & 2530 & 2.56 & 2.36 & 36 & 2.16 \\
\hline 0 & 2-1 Coal & 3 & 1820 & 1.92 & 1.62 & 24.2 & 1.89 \\
\hline-1 & $\begin{array}{l}\text { Sandy } \\
\text { mudstone }\end{array}$ & 30 & 2530 & 2.56 & 2.36 & 36 & 2.16 \\
\hline-2 & 2-2 Coal & 2 & 1820 & 1.92 & 1.62 & 24.2 & 1.89 \\
\hline
\end{tabular}




\subsection{Support Scheme of Auxiliary Haulage Roadway 21102}

As shown in Figure 2, the roof of AHR 21102 is supported by "blot + cable" at stage of excavating. The roof is supported by five $\Phi 20 \times 2200-\mathrm{mm}$ left-hand threaded steel bolts. Moreover, the bolts in the left wing and right wing had an indentation of $15^{\circ}$ and the rest were installed vertically. Each bolt is anchored by one MSCK $2370 \mathrm{~mm}$ resin coil and the pretension of bolt is $60 \mathrm{kN}$. In addition, two $\Phi 17.8 \times 6200 \mathrm{~mm}$ cables are arranged for two rows of anchor bolts in each interval as the reinforcement support. All the cables were installed vertically on the roof of the roadway. Each cable was anchored with two MSCK $2370 \mathrm{~mm}$ resin coils, with pretension of $130 \mathrm{kN}$. Furthermore, the inter-row spacing of the bolts and anchor cables is $1100 \times 1000 \mathrm{~mm}$ and $2200 \times 2000 \mathrm{~mm}$, respectively. Each row of non-mining side of roadway is supported by three $\Phi 20 \times 2200 \mathrm{~mm}$ left-hand threaded steel bolts and the row spacing between bolts is $1000 \times 1000 \mathrm{~mm}$. Besides, the top angle and bottom angle of coal side are installed with $15^{\circ}$ inclination and the rest bolts are installed vertically to the rock surface. Each bolt is anchored by one MSCK $2370 \mathrm{~mm}$ resin coil and the pretension of bolt is $30 \mathrm{kN}$, and each row of mining side is installed with three $\Phi 27 \times 2000 \mathrm{~mm}$ glass fiber-reinforced plastics bolts. Finally, the inter-row spacing of the bolts is $1000 \times 1000 \mathrm{~mm}$, and the pretension of the bolt is $12 \mathrm{kN}$.

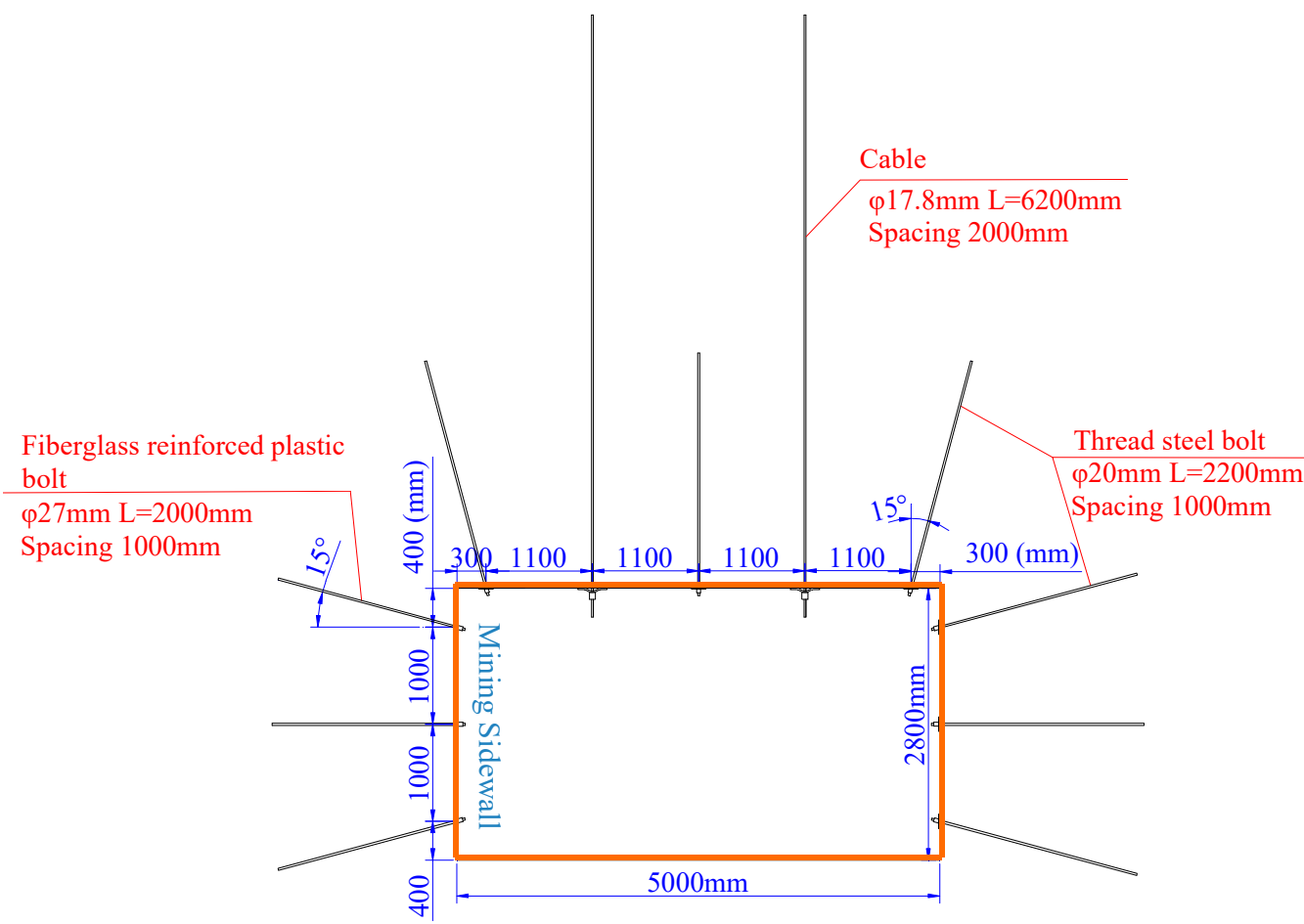

Figure 2. Support scheme of AHR 21102.

\subsection{Maintenance Status of AHR 21102}

Affected by the mining stress of the working face 21102, the AHR 21102 has a large deformation, and different roadway sections show different degrees of section contraction. The full section of roadway lane 2 and lane 4 (Figure 1) is pressed and shrinks violently, and the roof and floor of some sections are almost closed, relying on the wooden crib support (Figure 3), so it cannot be used as the return air roadway of the working face 21201. Although the surrounding rock of lane 1 , lane 3 , and lane 5 roadway section has large deformation, the stability structure of surrounding rock still exists. 


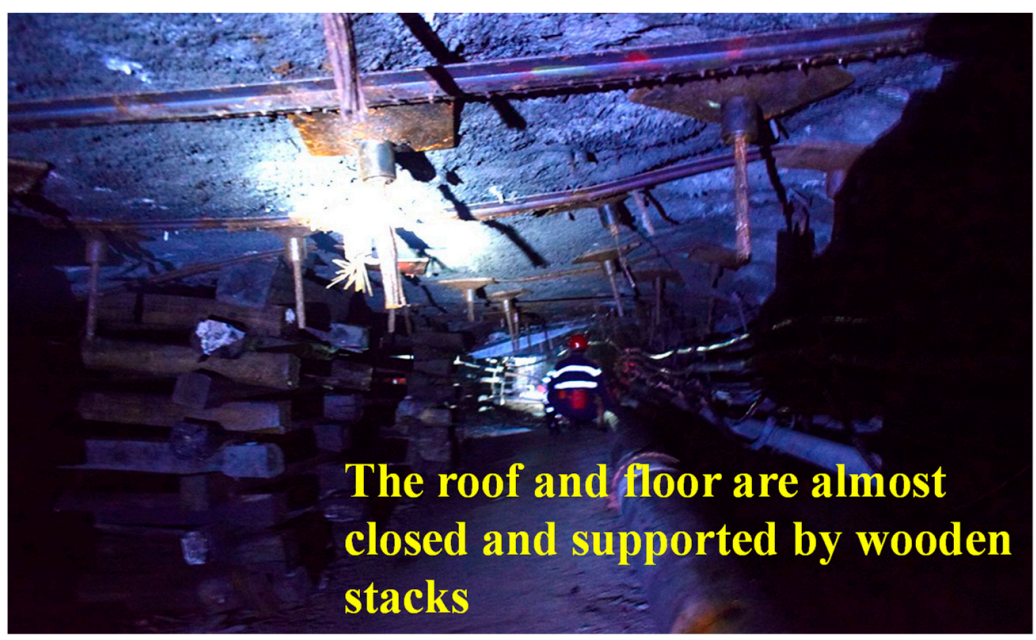

Figure 3. Maintenance effect of auxiliary haulage roadway 21102.

\section{Pressure Relief Mechanism of Roadway with Large Deformation}

\subsection{Principle of Pressure Relief of Roadway with Large Deformation}

Given that there is a 30-m wide coal pillar between AHR 21102 and working face 21102 , the high concentrated stress caused by working face 21102 mining mainly acts on the 30-m-wide coal pillar during the mining period of working face 21102. The wide coal pillar produces a large amount of deformation under the action of high stress, resulting in the whole cross section of the RAR 21201 being under great pressure and having great deformation and failure full section weighting and severe contraction. As a result, a certain range of pressure relief area is formed near the working face 21201. If the pressure relief effect of the surrounding rock caused by the violent deformation of AHR 21102 is used, the reasonable width narrow coal pillar is reserved at the working face 21201 side of AHR 21102 to excavate RAR 21201, so that the narrow coal pillar bears less stress, and the RAR 21201 is in the pressure relief zone, which is not only conducive to the maintenance of the roadway, but also improves the recovery rate of coal resources. Two coal pillars are formed on both sides of AHR 21102. One side is the residual $30 \mathrm{~m}$ wide coal pillar, which is called pressure-bearing pillar (Figure 4), and the other side is the protective coal pillar of 21201 return air roadway (hereinafter referred to as protective coal pillar). Because the protective coal pillar bears less stress, it is called a pressure-yielding pillar. The width of the pressure-yielding pillar is the key to determine whether the RAR 21201 can be in the effective pressure relief area.

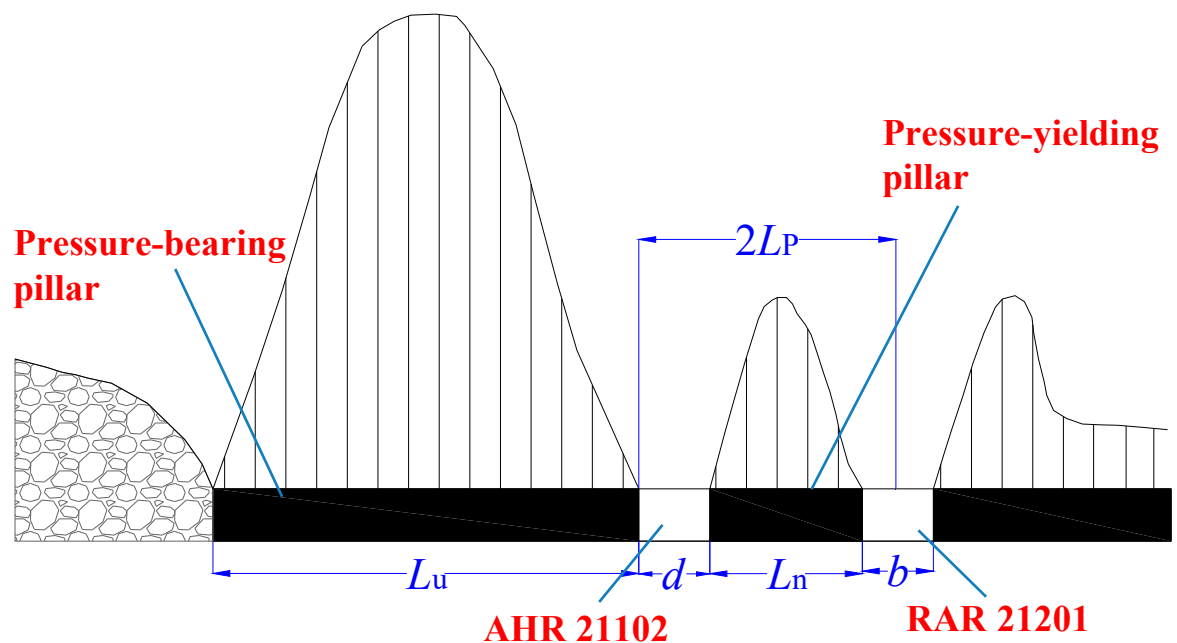

Figure 4. Stress distribution of AHR 21102. 


\subsection{Simulation Analysis of Pressure Relief Effect}

\subsubsection{Setting up the Numerical Model}

The finite difference FLAC3D numerical model is established based on the working face 21102, AHR 21102 and RAR 21201 with a coal pillar along the 21102 auxiliary haulage roadway. The model length $\times$ width $\times$ height $=270 \mathrm{~m} \times 120 \mathrm{~m} \times 78 \mathrm{~m}$ (Figure 5). The width of 21102 working face is $165 \mathrm{~m}$ (half, actual width is $330 \mathrm{~m}$ ), and the dimensions of 21102 auxiliary haulage roadway and 21201 return air roadway are width $\times$ height $=5 \mathrm{~m} \times 2.8 \mathrm{~m}$ (according to the actual cross-section size of roadway). In order to ensure the calculation accuracy, the grid of roadway and coal pillar area is designed to be densified. The upper end of the model is a free surface with a vertical load of $15 \mathrm{MPa}$ (calculated according to the actual buried depth of $626 \mathrm{~m}$ ). Besides, the displacement boundary conditions are applied both around and at the bottom of the model. The bottom boundary of the model is fixed in the vertical direction, while the left and right boundaries fixed in the horizontal direction to eliminate the displacement. Besides, the model adopts the Mohr-Coulomb yield criterion, and the physical parameters of rock stratum are shown in Table 1; the text related to Table 1 and the caption should clearly state the parameters were taken from [18-20] and that they represent rock mass properties while considering the effect of cleat networks in the coal seam.

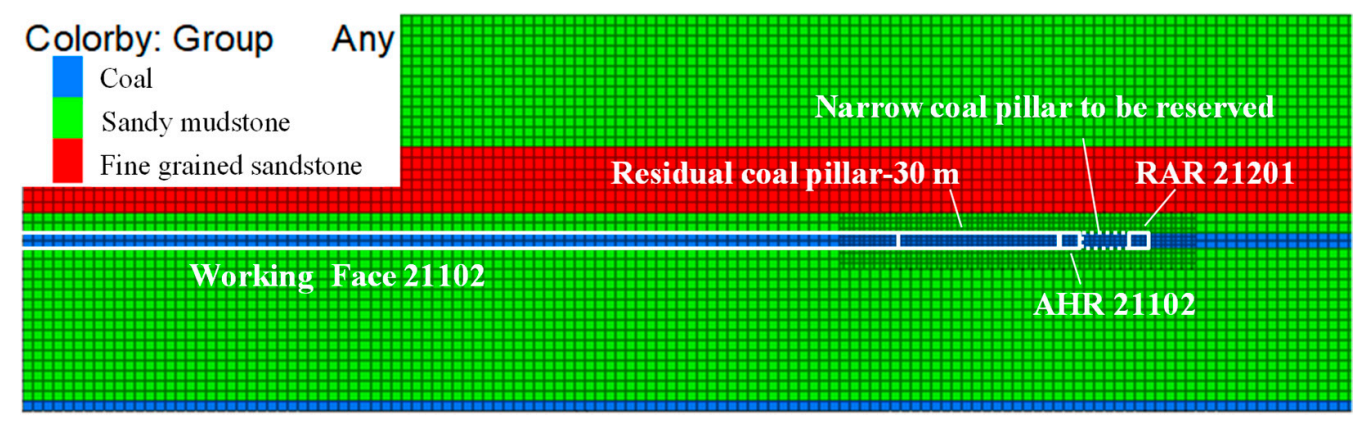

Figure 5. Numerical calculation model.

The numerical calculation process is as follows: original rock stress calculation $\rightarrow$ excavation of AHR $21102 \rightarrow$ mining of working face $21102 \rightarrow$ excavation of RAR 21201 by setting different width $(2 \mathrm{~m}, 4 \mathrm{~m}, 6 \mathrm{~m}, 8 \mathrm{~m}, 10 \mathrm{~m}, 12 \mathrm{~m}, 14 \mathrm{~m}, 16 \mathrm{~m}, 18 \mathrm{~m}, 20 \mathrm{~m})$ protective coal pillars.

\subsubsection{Calculation Results}

It can be concluded from Figure 6 that: (1) the $30 \mathrm{~m}$ residual coal pillar work is in cooperation and linkage with the protective coal pillar of the RAR 21201. When the width of the protective coal pillar is small (e.g., $2 \mathrm{~m}, 4 \mathrm{~m}, 6 \mathrm{~m}$ ), the vertical stress above the $30 \mathrm{~m}$ residual coal pillar is higher than that when the RAR 21201 is not excavated, and the vertical stress above the corresponding protective coal pillar is lower than that when the RAR 21201 is not excavated; (2) with the increase of coal pillar width $(2 \mathrm{~m} \sim 10 \mathrm{~m})$, the width of elastic core area in the coal pillar increases and begins to undertake higher concentrated stress, which makes the concentrated stress above the $30 \mathrm{~m}$ residual coal pillar decrease; (3) when the width of the coal pillar increases to a certain range (10 m 20 m), the RAR 21201 enters into the original rock stress area by avoiding the stress rising area, which is formed in the lateral solid coal after mining in the 21102 working face of the upper section. Therefore, the vertical stress above the coal pillar has a decreasing trend, at this time, the vertical stress above the $30 \mathrm{~m}$ residual coal pillar also gradually returns to the state when the RAR 21201 is not excavated; (4) the width of coal pillar should be less than $8 \sim 10 \mathrm{~m}$ when considering the pressure relief effect of surrounding rock caused by severe deformation of AHR 21102. 


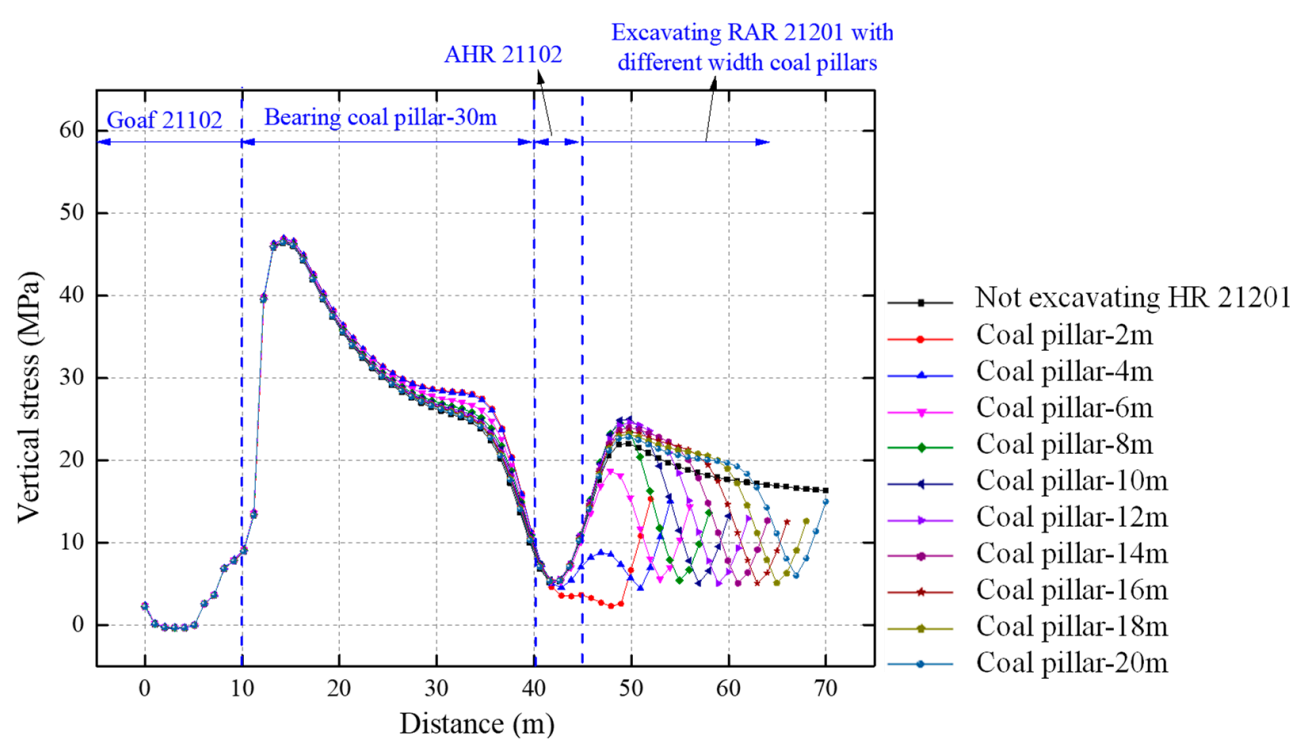

Figure 6. Stress analysis of roadway and coal pillar roof with different width coal pillars.

\section{Engineering Practice and Mining Pressure Monitoring}

\subsection{Determination of Coal Pillar Width of RAR 21201}

According to the calculation method of yield coal pillar width in [21], the width calculation method of pressure-yielding pillar is as follows:

$$
P=L_{\mathrm{p}} \gamma H
$$

where $L_{p}$ is the width of the roof loading zone of the yielding coal pillar. It can be concluded from Figure 4 that:

$$
L_{\mathrm{p}}=\left(0.5 b+L_{\mathrm{n}}+d\right) / 2
$$

where $b, d$ is the width of RAR 21201 and AHR 21102 respectively, which is $2.8 \mathrm{~m}$ according to the actual width of the two roadways; $H$ is the buried depth of roadway, which is $620 \mathrm{~m}$; and $\gamma$ is the volume weight of overlying strata, which is $25 \mathrm{kN} / \mathrm{m}^{3}$.

The ultimate bearing load of the protective coal pillar of return air roadway is as follows:

$$
Q=L_{\mathrm{n}} R\left(L_{\mathrm{n}} / M\right) 2 / 3
$$

where: $R$ is the ultimate compressive strength of pressure-yielding pillar, which is $15 \mathrm{MPa}$. The concentration factor of abutment pressure in advance of working face is $\mathrm{k}=3$. Making $k P=\mathrm{Q}$, we can get the limit coal pillar (pressure-yielding pillar) $L_{\mathrm{n}}=10.9 \mathrm{~m}$. Combined with the results of numerical simulation and engineering practice, the coal pillar width of RAR 21201 is determined to be $10.75 \mathrm{~m}$.

\subsection{Support Scheme Design \\ 4.2.1. Roof Supporting}

In the previous support scheme, the length of bolt and cable is quite different, and the outer layer of bolt anchoring zone is borne by cable, but the density of the cable is low. When the cable is too close to the bolt, the anchoring stress interferes with each other, resulting in poor group supporting effect. Due to the different mechanical properties of bolt and cable, it is difficult to carry the load cooperatively. The early load is mainly concentrated on the cable with higher pretension and stronger sensitivity. In case of strong dynamic pressure, the cable is often broken first and then the bolt is broken again, and the support system is broken by each one. In order to promote the bolt and cable cooperative bearing support, the previous support scheme should be optimized, and the optimized support scheme is as follows: 
The roof adopts the "bolt + cable" equal row spacing double-bearing ring support technology $[22,23]$.

(1) Bolt support: The roof is supported by six $\Phi 20 \times 2200 \mathrm{~mm}$ left-hand threaded steel bolts (Figure 7). The bolts in the left wing and right wing have an indentation of $15^{\circ}$ and the rest are installed vertically. Each bolt is anchored by one MSCK $2370 \mathrm{~mm}$ resin coil and the pretension of bolt is $60 \mathrm{kN}$, and the inter-row spacing of the bolts is $1100 \times 2000 \mathrm{~mm}$.

(2) Cable support: Each row of the roof is supported by four $\Phi 21.8 \times 4300 \mathrm{~mm}$ cables, all of which are vertical to the roof of roadway. Each cable is anchored by two MSCK $2370 \mathrm{~mm}$ resin coils, and the pretension is $200 \mathrm{kN}$.

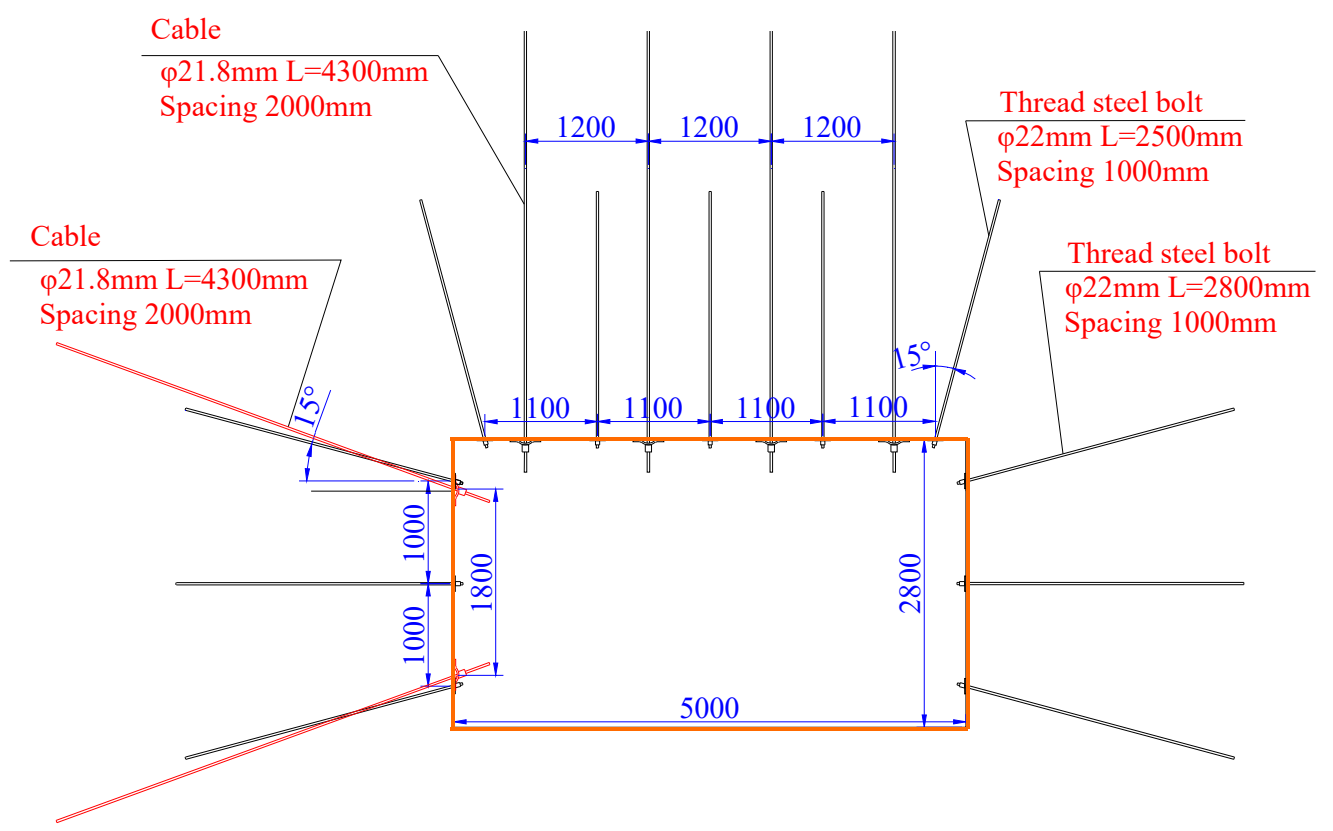

Figure 7. Support scheme of RAR 21201.

\subsubsection{Coal Rib of Roadway Supporting}

The "bolt + cable" combined support is adopted for the coal rib, that is, the highstrength screw steel bolt is used as the foundation support for both ribs, and the cable is used as the reinforcement support for the side of the coal pillar.

(1) Foundation support: Each row of the coal rib is supported by three left-hand threaded steel bolts with diameter of $22 \times 2800 \mathrm{~mm}$ and diamond-shaped metal mesh; the inter-row spacing of the bolts is $1000 \times 1000 \mathrm{~mm}$; the top angle and bottom angle of coal side are installed with $15^{\circ}$ inclination; and the rest bolts are installed vertically to the rock surface. Each bolt was anchored by one MSCK $2370 \mathrm{~mm}$ resin coil and the pretension of bolt is $60 \mathrm{kN}$.

(2) Reinforced support at the side of coal pillar: Every two rows of bolts are reinforced by two $\Phi 21.8 \times 4300 \mathrm{~mm}$ cables; the inter-row spacing of the bolts is $1800 \times 1000 \mathrm{~mm}$. The upper and lower anchor cables are installed at an external angle of $20^{\circ}$, and each cable is anchored with two MSCK $2370 \mathrm{~mm}$ resin coils with a pretension of $200 \mathrm{kN}$.

\subsection{Mine Pressure Monitoring}

\subsubsection{Monitoring of Roadway Surface Displacement}

During roadway excavation, four roadway surface displacement measuring stations are arranged: numbered WY1, WY2, WY3, and WY4 in turn. Among them, WY1 and WY2 measuring stations are arranged in the 21201 roadway corresponding to roadway lane 1 (Figure 1); WY3 and WY4 measuring stations are arranged in the 21201 roadway corresponding to roadway lane 2 . The cross section method is adopted for monitoring. The displacement curves of the four measuring stations are shown in Figure 8. 


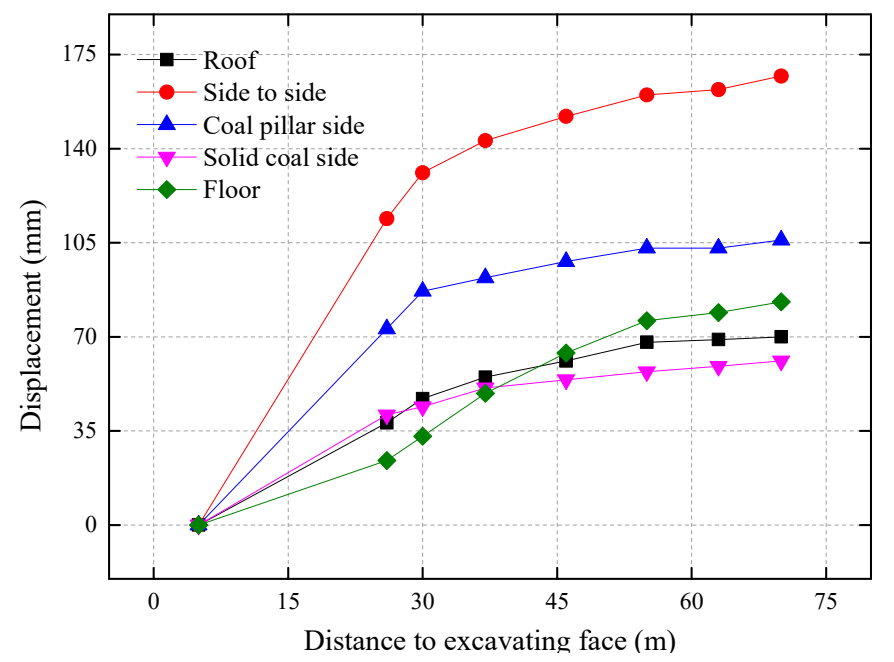

(a)

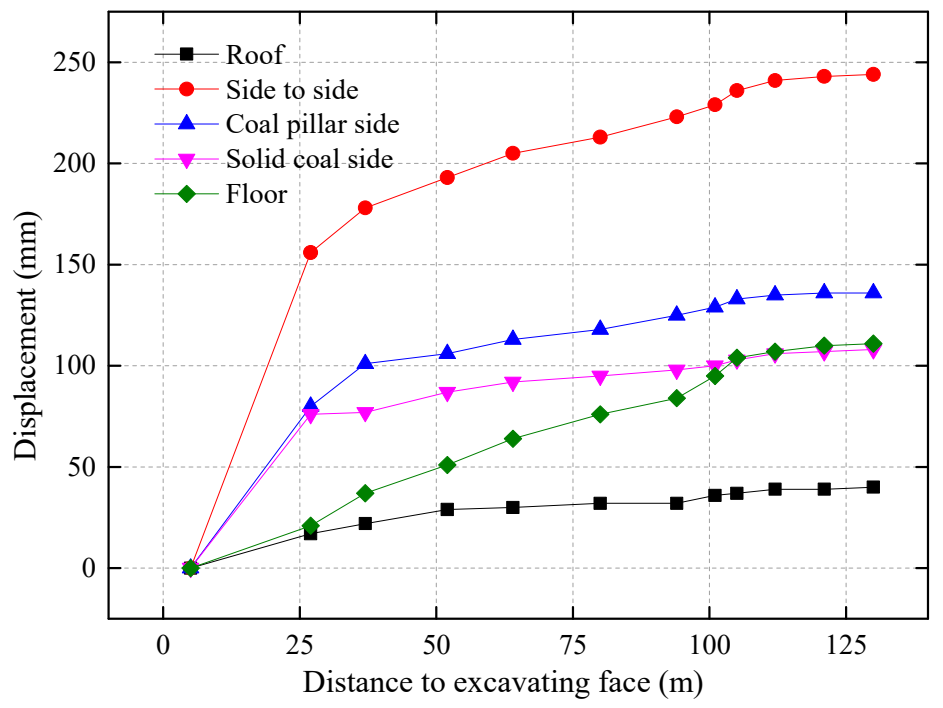

(b)

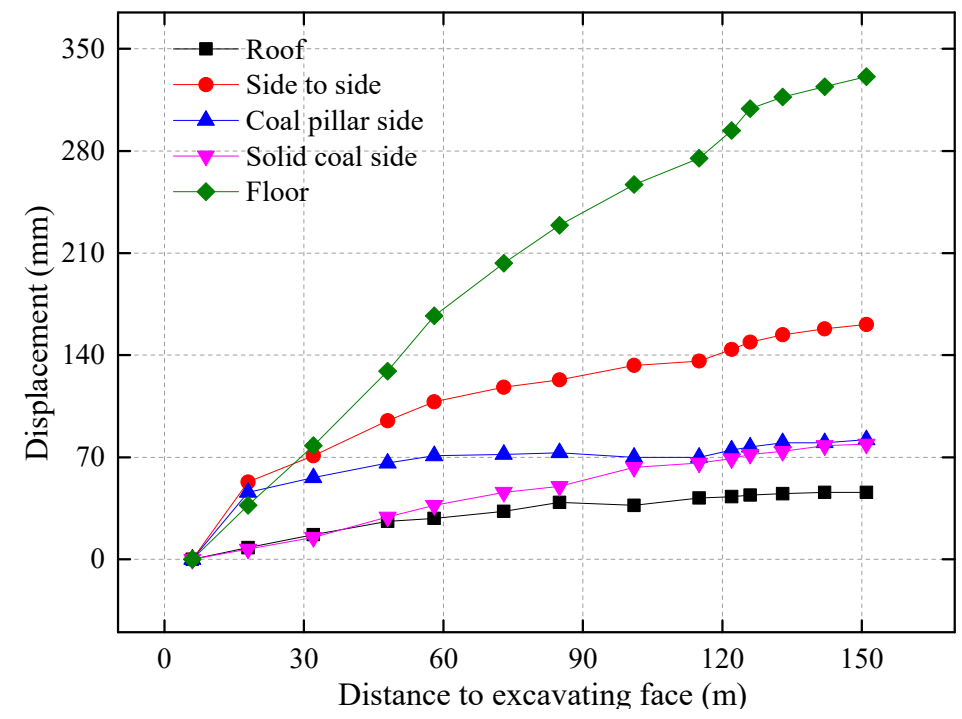

(c)

Figure 8. Cont. 


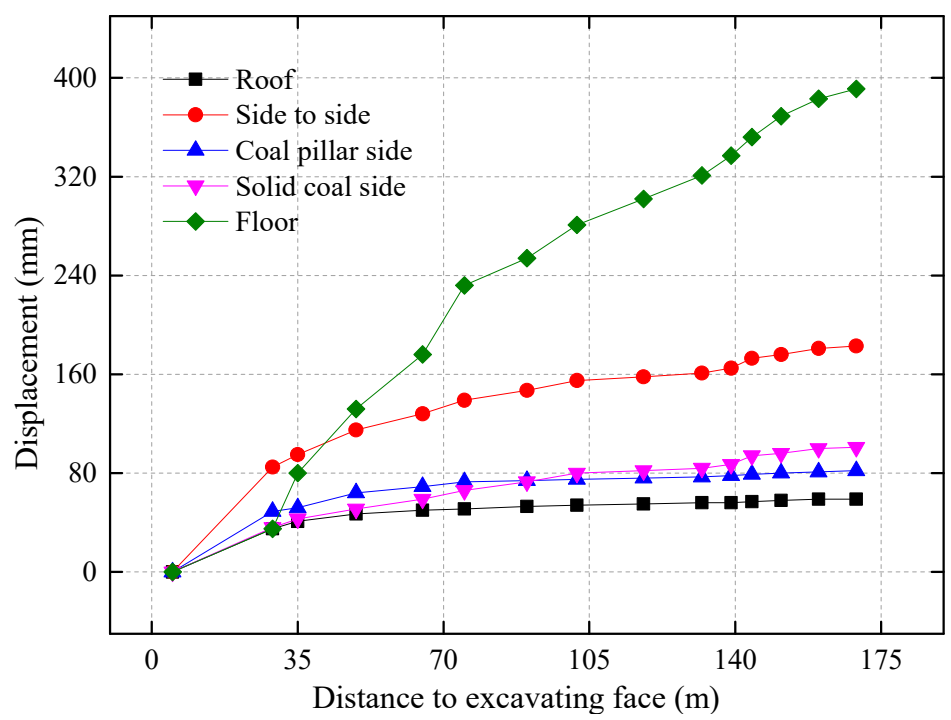

(d)

Figure 8. Surface displacement of the RAR 21201 versus distance to excavation face. (a) The monitoring results of $\mathrm{WH} 1$ station; (b) the monitoring results of $\mathrm{WH} 2$ station; (c) the monitoring results of WH3 station; and (d) the monitoring results of WH4 station.

(1) Within the range of 30 50 $\mathrm{m}$ away from the excavating face, the monitoring results of the four stations show that the deformation of two ribs and roof subsidence increase rapidly, showing a linear growth trend. When the distance between the station and the excavating face exceeds $50 \mathrm{~m}$, with the weakening of the dynamic pressure disturbance, the deformation decreases significantly, then tends to be stable, and finally enters the rheological period. After stability, the maximum deformation of the middle point of the roof is $35 \sim 70 \mathrm{~mm}$, and the maximum displacement of two ribs is $161 \sim 244 \mathrm{~mm}$. In addition to the station of $\mathrm{WH} 1$, the deformation of coal pillar side is slightly larger than that of solid coal side.

(2) The deformation of the floor varies from the four stations among which the floor deformation of WY1 and WY2 station is more severe. With the increasing distance between station and excavating face, the amount and rate of deformation have no obvious trend of stabilization. During the monitoring period, the maximum floor deformations of WY1 and WY2 station are $391 \mathrm{~mm}$ and $331 \mathrm{~mm}$ respectively. On the contrary, the corresponding floor deformations of WY3 and WY4 station is relatively mild, and the floor deformation tends to be stable with the weakening of driving dynamic pressure disturbance. The maximum floor deformations of WY3 and WY4 station are $111 \mathrm{~mm}$ and $83 \mathrm{~mm}$ respectively. Compared with WY1 and WY2 station, the floor deformations of the WY3 and WY4 are obviously improved.

\subsubsection{Roof Separation Crack Monitoring}

There are two boreholes in the roof separation cracks of roadway, numbered ZK1 and ZK2 in turn, which are respectively located in the 21201 roadway corresponding to roadway Section 1 and roadway Section 2 . The integrity of roof strata reflected by drilling is shown in Figure 9. Results of two boreholes show that there are no obvious separation cracks inside and outside the anchorage zone of roof bolt and anchor cable, and the roof integrity is good.

The results indicate that the "bolt + cable" equal row-spacing double-bearing ring support technology can effectively control the development of internal and external separation cracks in the roof anchorage zone, and finally guarantee the integrity and stability of the roof deep surrounding rock. 


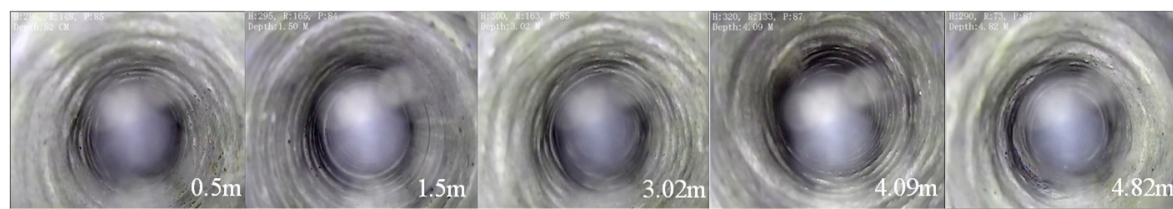

(a)

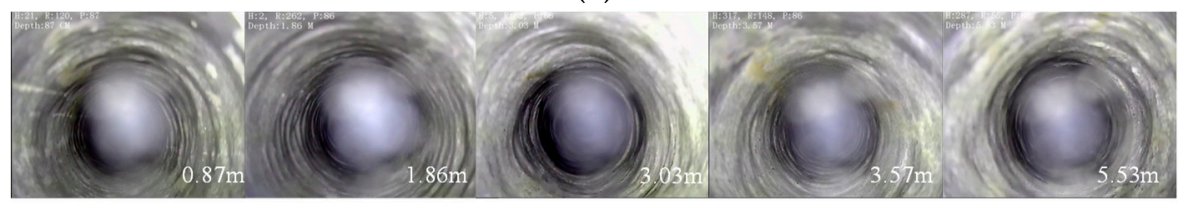

(b)

Figure 9. Monitoring results of roadway roof fracture. (a) The monitoring results of ZK1 station; (b) the monitoring results of ZK2 station.

\section{Roadway Maintenance Effect and Discussion}

\subsection{Roadway Surrounding Rock Control Effect}

RAR 21201 has been excavated for nearly $700 \mathrm{~m}$, whose excavating face is located in the corresponding roadway section of roadway lane 2 . According to the control effect of roadway surrounding rock, the roof rock layers of the two roadway lanes are relatively complete, showing no obvious separation cracks both inside and outside the anchorage zone. Besides, there are significant differences in the construction conditions, which are shown as follows: When the roadway is excavating into the corresponding roadway lane 1: (1) Floor heave appears generally in the roadway, whose amount is $300 \sim 400 \mathrm{~mm}$, and the floor heave time generally begins to appear after 2 days of roadway excavation; (2) the mine pressure behavior of two ribs vary obviously, meanwhile, the coal pillar side shows the phenomenon of vertical outward coal block collapse. Besides, the sound of coal gun is frequent, and the solid coal side is relatively gentle. (3) Hole collapse and top drilling easily occurs when building cables on the coal pillar side, which leads to the longest construction time of single bolt up to $45 \mathrm{~min}$ (repeated hole collapse). On the contrary, when the roadway is excavated into the corresponding roadway lane 2: (1) The floor heave phenomenon is obviously improved, with floor heave of $80 \sim 120 \mathrm{~mm}$; (2) Coal block collapse and coal gun sound still occur from time to time, with decreased frequency; (3) The problems of hole collapse and top drilling are greatly alleviated during the construction of a cable on the coal pillar side.

\subsection{Discussion}

(1) At present, RAR 21201 has been excavated for nearly $700 \mathrm{~m}$. Due to the different deformation degrees of roadway lane 1 and lane 2, the two roadway sections of RAR 21201 have shown obvious differences in construction. In the roadway section corresponding to lane 1, the surrounding rock structure of AHR 21102 has not been completely destroyed, and the roof stress has not been fully released. Meanwhile, the protective coal pillar of RAR 21201 still bears large stress, resulting in the strong mining pressure behaviors such as severe floor heave, frequent coal gun sound, hole collapse, and top drilling in the construction of coal pillar side. After entering the roadway lane 2, the severe deformation of the residual roadway effectively releases high concentrated stress of the roof, which informs a pressure relief effect on the surrounding rock. When excavating the RAR 21201, the floor heave, the frequent sound of coal guns, the hole collapse and top drilling in the construction of coal pillar side, and other strong mine pressure phenomena are obviously improved, which means the surrounding rock control effect is good (Figure 10). 


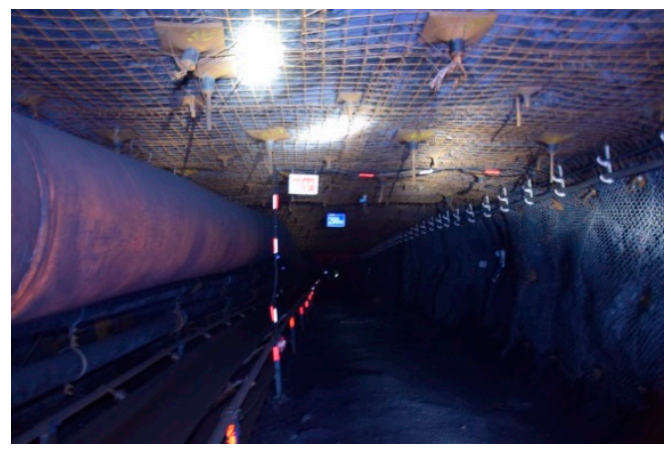

(a)

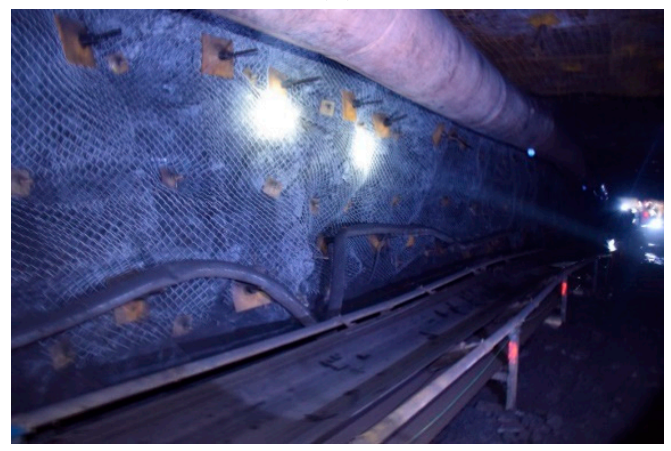

(b)

Figure 10. Overall maintenance of roadway. (a) Overall section maintenance of roadway; (b) maintenance effect of coal pillar side.

(2) According to the field construction situation and surrounding rock control effect of two roadway lanes, when the coal pillar of 21201 return air roadway is $10.75 \mathrm{~m}$, it bears large vertical stress, which is reflected in severe floor heave, coal gun sound, hole collapse, and top drilling of coal pillar side construction (when excavating to the section of lane 1). Even so, the severe deformation section of AHR 21102 still has a pressure relief effect on RAR 21201, which is reflected in the improved equal strength mine pressure phenomenon when excavating to the section of lane 2. In order to achieve high efficiency and safety of later excavation to the mild deformation section, it is necessary to further detect the width of the broken area and the elastic core width of the protective coal pillar. In addition, it is necessary to try to further narrow the width of the roadway pillar, as well as make full use of the pressure relief effect of the severe deformation of AHR 21102 on the surrounding rock, and finally create a good stress environment for the maintenance of a new excavated roadway.

\section{Conclusions}

(1) Severe deformation of deep roadway can exert a pressure relief effect on surrounding rock mass. The results of numerical simulation show that the pressure relief effect declines with the increase of the width of the coal pillar of RAR 21201. When the width of the coal pillar increases to a certain range, the pressure relief effect basically disappears.

(2) The mine pressure monitoring results of RAR 21201 show that the pressure relief effect of RAR 21201 is not obvious when the deformation of AHR 21102 is relatively mild. During the construction of the roadway, the strong mine pressure phenomenon is obvious including severe floor heave, frequent coal gun soundm and repeated hole collapse during the construction of cable on the coal pillar side. In the section of AHR 21102 with severe deformation, the above-mentioned strong mine pressure problems are significantly improved during the construction of RAR 21201, showing an optimistic pressure relief effect. It proves that the severe deformation of AHR 21102 has pressure relief effect on RAR 21201. 
(3) Equal row-spacing double-bearing ring support technology can effectively control the surrounding rock deformation of RAR 21201. As soon as entering the pressure relief area, there is no obvious separation crack development in the roof, and the surrounding rock deformation is well controlled. After stability, the maximum deformation of the midpoint of the roof is $35 \sim 70 \mathrm{~mm}$, and the control effect is good.

(4) In the follow-up study, it is worth further studying the deformation degree of different sections in AHR 21102. When excavating to the mild deformation section of auxiliary haulage roadway 21102 , the width of broken zone and elastic core of roadway pillar of RAR 21201 should be further detected so to ensure efficient and safe construction. Besides, through a narrower width of coal pillar and application of pressure relief effect on surrounding rock, a better stress environment can be created to maintain RAR 21201.

Author Contributions: Data curation-H.Y.; Formal analysis-H.Y., N.Z. and C.H.; Funding acquisition-H.Y.; Investigation-H.Y. and C.S.; Project administration-N.Z. and C.H.; Writingoriginal draft-H.Y.; Writing-review \& editing-H.Y., N.Z., C.H., G.S., Y.S., K.S. All authors have read and agreed to the published version of the manuscript.

Funding: This work was supported by the Postgraduate Research \& Practice Innovation Program of Jiangsu Province (KYCX20_2016), Future Scientists Program of China University of Mining and Technology (2020WLKXJ010).

Institutional Review Board Statement: Not applicable.

Informed Consent Statement: Not applicable.

Data Availability Statement: Data is contained within the article.

Acknowledgments: The authors are very grateful to the reviewers for carefully reading the manuscript and providing valuable suggestions. Houqiang Yang wants to particularly thank his teachers and girlfriend Suwan Yu for their support.

Conflicts of Interest: The authors declare no conflict of interest.

Abbreviations
$\begin{array}{ll}\text { AHR 21102 } & \text { auxiliary haulage roadway } 21102 \\ \text { RAR 21201 } & \begin{array}{l}\text { return air roadway 21201 } \\ \text { The first monitoring station of roadway surface displacement }\end{array} \\ \text { WH1 } & \text { The second monitoring station of roadway surface displacement } \\ \text { WH2 } & \text { The third monitoring station of roadway surface displacement } \\ \text { WH3 } & \text { The forth monitoring station of roadway surface displacement } \\ \text { WH4 } & \text { The first monitoring station of roadway roof fracture } \\ \text { ZK1 } & \text { The second monitoring station of roadway roof fracture } \\ \text { ZK2 } & \end{array}$

\section{References}

1. Wang, J.H.; Kang, H.P.; Liu, J.Z.; Chen, P.P.; Fan, Z.Z.; Yuan, W.M.; Liu, Y.P. Layout strategic research of green coal resource development in China. J. China Univ. Min. Technol. 2018, 47, 15-20.

2. Yao, Q.L.; Tang, C.J.; Liu, Z.C. Discussion on coal and water co-mining in ecologically fragile mining areas in western China. Coal Sci. Technol. 2020, 1-7. Available online: http://kns.cnki.net/kcms/detail/11.2402.TD.20200215.2005.008.html (accessed on 17 February 2020).

3. Yuan, L.; Zhang, T.; Zhao, Y.X.; Ren, B.; Hao, X.J.; Xu, C. Precise coordinated mining of coal and associated resources: A case of enviromental coordinated mining of coal and associated rare metal in Ordos basin. J. China Univ. Min. Technol. 2017, 46, 449-459.

4. Sun, Y.T.; Li, G.C.; Zhang, J.F. Investigation on jet grouting support strategy for controlling time-dependent deformation in the roadway. Energy Sci Eng. 2020, 8, 2151-2158. [CrossRef]

5. Yuan, L. Strategic thinking of simultaneous exploitation of coal and gas in deep mining. J. China Coal Soc. 2016, 41, 1-6.

6. Xie, H.P.; Zhou, H.W.; Xue, D.J.; Wang, H.W.; Zhang, R.; Gao, F. Research and consideration on deep coal mining and critical mining depth. J. China Coal Soc. 2012, 37, 535-542.

7. Wang, Z.Q.; Su, Y.; Song, Z.Y.; Shi, L.; Sun, Z.W. Technology and application effect analysis of gob-side entry driving for super-long two-entry longwall panel. Chin. J. Rock Mech. Eng. 2018, 37, 4170-4176. 
8. Wang, Z.Q.; Wang, H.H.; Shi, L.; Su, Y. Sequential extraction technology for high-intensity super-long two-entry longwall panels. J. China Coal Soc. 2017, 42, 302-310.

9. Dong, Y.D.; Yao, W.; Liu, Y.H. Strong mining pressure treatment in double lane layout working face with large mining depth and high ground stress. Coal Sci. Technol. 2018, 46, 103-107.

10. Wang, B.; Jiang, F.X.; Zhu, S.T.; Qu, X.C.; Zhang, X.F.; Wei, Q.D.; Wu, Z.; Xie, H.D. Mechanism and prevention of rock burst induced by segment pillars in the deep mining areas of Shaanxi-Inner Mongolia adjacent regions. J. Min. Saf. Eng. 2020, 37, 505-513.

11. Zheng, J.; Ju, W.; Sun, X.; Li, Z.; Wang, S.; Liu, B. Large Deformation Mechanics of Gob-Side Roadway and Its Controlling Methods in Deep Coal Mining: A Case Study. Adv. Civ. Eng. 2020, 2020, 1-13. [CrossRef]

12. Tai, Y.; Yu, B.; Xia, B.; Li, Z.; Xia, H. Research on stress release for the gob-side roadway using the roof-cutting technology with a chainsaw arm. R. Soc. Open Sci. 2020, 7, 191663. [CrossRef] [PubMed]

13. Zhang, Y.; Yang, Y.; Zhuge, C. Deformation Caused by Dynamic Load and Support Requirements in a Deep Gob-Side Entry Rock Mass. Adv. Mater. Sci. Eng. 2019, 2019, 1-16. [CrossRef]

14. Wu, W.-D.; Bai, J.-B.; Wang, X.-Y.; Yan, S.; Wu, S.-X. Numerical Study of Failure Mechanisms and Control Techniques for a Gob-Side Yield Pillar in the Sijiazhuang Coal Mine, China. Rock Mech. Rock Eng. 2019, 52, 1231-1245. [CrossRef]

15. Zhang, K.X.; Jiang, Y.D.; Zhang, Z.B.; Zhang, Y.P.; Pang, X.F.; Zeng, X.T. Determining the reasonable width of narrow pillar of roadway in gob entry driving in the large pillar. J. Min. Saf. Eng. 2014, 31, 255-262.

16. Mohan, G.M.; Sheorey, P.; Kushwaha, A. Numerical estimation of pillar strength in coal mines. Int. J. Rock Mech. Min. Sci. 2001, 38, 1185-1192. [CrossRef]

17. Wattimena, R.; Kramadibrata, S.; Sidi, I.; Azizi, M. Developing coal pillar stability chart using logistic regression. Int. J. Rock Mech. Min. Sci. 2013, 58, 55-60. [CrossRef]

18. Xie, Z.; Zhang, N.; Feng, X.; Liang, D.; Wei, Q.; Weng, M. Investigation on the evolution and control of surrounding rock fracture under different supporting conditions in deep roadway during excavation period. Int. J. Rock Mech. Min. Sci. 2019, 123, 104122. [CrossRef]

19. Xie, Z.; Zhang, N.; Meng, F.; Han, C.; An, Y.; Zhu, R. Deformation Field Evolution and Failure Mechanisms of Coal-Rock Combination Based on the Digital Speckle Correlation Method. Energies 2019, 12, 2511. [CrossRef]

20. Yang, H.; Han, C.; Zhang, N.; Pan, D.; Xie, Z. Research and Application of Low Density Roof Support Technology of Rapid Excavation for Coal Roadway. Geotech. Geol. Eng. 2019, 38, 389-401. [CrossRef]

21. Lu, Y.; Zou, X.Z.; Liu, C.Y.; Xing, S.J. Technology of Digging Stress-Relax Entryby the Roadside and Its Application. J. Min. Saf. Eng. 2006, 3, 329-332.

22. Han, C.L.; Zhang, N.; Kan, J.G.; Ran, Z. Mechanism and application of double active control with pressure-relieving and anchoring for gob-side entry retaining. J. China Coal Soc. 2017, 42, 323-330.

23. Yang, H.; Han, C.; Zhang, N.; Sun, C.; Pan, D.; Dong, M. Stability Control of a Goaf-Side Roadway under the Mining Disturbance of an Adjacent Coal Working Face in an Underground Mine. Sustainability 2019, 11, 6398. [CrossRef] 